\title{
La traducción de los aspectos interculturales en el aula de ELE con alumnos polacos de nivel inicial
}

\author{
Intercultural references in Translation: \\ beginner learners of Spanish \\ as a Foreign Language. The case of Polish students
}

\author{
Verónica Del Valle Cacela \\ Uniwersytet Marii Curie-Skłodowskiej w Lublinie (Polonia) \\ veronica.delvalle@poczta.umcs.lublin.pl
}

\begin{abstract}
Translation encompasses a complex activity in which we must transfer ideas from a source language to a target language, so that knowledge of the environment surrounding the working languages becomes a necessary competence to carry out the translation activity. Within this knowledge, we must necessarily include the cultural aspects of a language, either from an intercultural or an intracultural perspective. For the purpose of this article, we will focus on how intercultural elements can be developed in the classroom of Spanish as a foreign language. In order to accomplish our aim, we will expose based on empirical analysis the introduction of sociocultural items in university studies with beginners learners (A1-A2) and the result obtained, knowing that the primary objective of this curriculum is to prepare students to be translators or interpreters.
\end{abstract}

Keywords: intercultural competence, translation, teaching L2/FL, sociocultural elements, didactics of translation

\section{LA IMPORTANCIA DE LA CULTURA EN EL AULA DE ELE}

La enseñanza-aprendizaje de una segunda lengua dejó de centrarse, hace tiempo, en cuestiones puramente lingüísticas para abarcar una realidad más amplia, es decir, para incluir y desarrollar en el aula todos aquellos elementos que acompañan y favo- 
recen el entendimiento de una lengua. Uno de estos aspectos es el papel de la cultura en la enseñanza-aprendizaje de lenguas extranjeras. De hecho, se trata de uno de los puntos que recoge el Marco Común Europeo de Referencia (Consejo de Europa, 2001). En este documento nos encontramos con varios apartados que mencionan la importancia del aspecto cultural a la hora de enseñar una lengua. Más concretamente, los puntos que inciden en este aspecto se encuentran en el apartado 5. No obstante, y a pesar de la importancia de que se incluya como punto de referencia, se trata de una cuestión tratada de manera superficial que se inicia con una mención al conocimiento sociocultural (5.1.1.2) para, posteriormente, introducir el concepto de consciencia intercultural. Esta se define del siguiente modo:

El conocimiento, la percepción y la comprensión de la relación entre el «mundo de origen» y el «mundo de la comunidad objeto de estudio» (similitudes y diferencias distintivas) producen una consciencia intercultural, que incluye, naturalmente, la conciencia de la diversidad regional y social en ambos mundos, que se enriquece con la conciencia de una serie de culturas más amplia de la que conlleva la lengua materna y la segunda lengua, lo cual contribuye a ubicar ambas en su contexto. Además del conocimiento objetivo, la consciencia intercultural supone una toma de conciencia del modo en que aparece la comunidad desde la perspectiva de los demás, a menudo, en forma de estereotipos nacionales (p. 101).

Se trata, pues, de relacionar esas dos culturas que se encuentran en el aula cuando un estudiante extranjero aprende español como lengua extranjera o segunda lengua, lo que constituye el objeto del presente artículo.

Comprobamos que no se trata de una definición muy específica sino que engloba ideas generales. Posteriormente, en el apartado 5.1.2.2, se intenta desarrollar esta definición sin éxito, pues se trata de una enumeración de lo mencionado anteriormente. Por tanto, delimitar qué características culturales incluiremos en el aula de ELE es una tarea compleja, ya que como indica Corti $(2019$, p. 24): "al liberar los conocimientos culturales de su carácter normativo, asociado a una concepción de alta cultura, el paradigma intercultural ha permitido la inclusión de una variedad de situaciones comunicativas por definición más amplia".

Esto implica que no tratemos solamente temas relacionados con el cine, la música, el arte o la literatura, por mencionar algunos de ellos, sino que la inclusión es mucho más amplia. Por consiguiente, tomaremos en consideración aspectos que son entendidos por los hablantes de una lengua y que interfieren en su aprendizaje-enseñanza. Para una comunicación más efectiva, el aprendiente debe conocer estas cuestiones y relacionarlas como una unidad integradora de la lengua. No se trata solo de evitar el choque cultural, sino también de comprender adecuadamente la compleja realidad en la adquisición de cualquier lengua extranjera. 


\section{LA COMPETENCIA INTERCULTURAL}

Si intentar definir el concepto 'cultura' presupone tomar en consideración diversos ámbitos de aplicación para crear una definición que pudiera ser aceptada por todos, la definición del concepto 'intercultura' tampoco resulta una tarea sencilla. Cuando pensamos en elementos interculturales, lo más habitual es que se piense en la contextualización de aquellos elementos intrínsecamente relacionados con una cultura y que no se comparten en otra, o bien, sí parecen compartirlas, pero con matices. Como bien lo señala Corti $(2019$, p. 20):

Si en el pasado se presentaban aspectos de una cultura como productos o prácticas que se podían describir de manera definida y aplicarse a amplios grupos de la sociedad, la interculturalidad propone por su lado una versión dialógica que posiciona al aprendiente frente a fenómenos culturales concretos, pero variables y dependientes del contexto. Las consecuencias de dicho giro son varias.

No en vano, el Diccionario de términos clave de ELE del Instituto Cervantes señala que se entenderá por interculturalidad aquella "relación que se establece intencionalmente entre culturas y que propugna el diálogo y el encuentro entre ellas a partir del reconocimiento mutuo de sus respectivos valores y formas de vida". Estamos, por tanto, ante un ejercicio contrastivo entre la cultura de la L1 y la cultura de la L2/LE en el que habrá que dirigir al aprendiente para que adquiera esta competencia intercultural, pues dicha competencia también sigue un proceso de adquisición, a saber:

Nivel monocultural: el aprendiente observa la cultura extranjera desde los límites interpretativos de su propia cultura;

Nivel intercultural: el aprendiente toma una posición intermedia entre la cultura propia y la extranjera, lo cual le permite establecer comparaciones entre ambas; y, finalmente, Nivel transcultural: el aprendiente alcanza la distancia adecuada respecto a las culturas en contacto para desempeñar la función de mediador entre ambas (Diccionario de términos clave de ELE, s.v. competencia intercultural).

Cabría pensar que el aprendiente de nivel inicial (A1-A2) se mantuviese en el primer estadio, ya que, normalmente, el aprendiente estudia la LE/L2 en su propio país. Por tanto, al no hallarse en una situación de inmersión, se podría caer en el error de creer que le falta información para establecer una comparación entre culturas. Sin embargo, y como veremos más adelante, el encontrarse en una primera fase de aprendizaje de la lengua extranjera no le impide avanzar hasta el siguiente estadio (nivel intercultural) y que siempre fue el objetivo principal de nuestro planteamiento. 


\section{LA TRADUCCIÓN DE ELEMENTOS CULTURALES}

El estudiante de nivel inicial no tiene por qué estar abocado a entender la cultura de forma unidireccional, ya que su primer objetivo es adquirir el conocimiento básico de una lengua extranjera. No obstante, cuando tratamos el ámbito de la traducción, uno podría presuponer que el conocimiento limitado de la lengua sea un problema para empezar a desarrollar estrategias traductológicas. Más aún, si el objeto de la traducción es intentar trasladar elementos culturales de la lengua de origen a la lengua meta. Sin embargo, estamos de acuerdo con el punto de vista de Igareda (2011), quien expone:

Bien es sabido que en cualquier tipo de traducción, sea cual sea el género y tipo de texto, la persona responsable del encargo realiza una doble operación: compara culturas y compara lenguas. Su trabajo necesita atender a determinados elementos de suma importancia, como son los aspectos socioculturales de ambas culturas (original y meta), la finalidad e intención de la traducción, el conocimiento de la cultura meta sobre todos los contenidos del texto original, los aspectos ideológicos y los profesionales, entre muchos otros (p. 12).

Por consiguiente, introducir al estudiante de nivel inicial en conceptos traductológicos, focalizando los elementos culturales, parece un ejercicio necesario, ya que la realidad cultural y la realidad lingüística necesitan la una de la otra para su funcionalidad. En la enseñanza-aprendizaje de lenguas se antoja improbable separarlas, dejando los aspectos culturales para niveles más avanzados, pues, incluso en la comunicación más esencial, se necesitan esos conocimientos culturales para comprender la lengua y evitar, por ejemplo, malentendidos:

En la traducción, emisor y receptor pertenecen a entidades culturales diferentes y hablan idiomas distintos. También las formas del comportamiento no verbal pertenecen a un código cultural. De modo que los emisores y receptores necesitan ayuda de alguien que esté familiarizado con ambas culturas (y lenguas), y que esté dispuesto a tomar el papel de intermediario o mediador entre ambos, es decir de traductor o intérprete (Nord, 2009, p. 210).

Este papel de mediador o intermediario es una constante en el ejercicio de la traducción, independientemente de la temática que se esté tratando, es decir, no es necesario observar la cultura como algo explícito dentro del discurso escrito $u$ oral de la lengua meta, sino presentarla como un elemento implícito y que, por ende, sea una cuestión relevante en distintos grados, teniendo en cuenta el encargo que debamos realizar. Como señala Igareda (2011, p. 14):

A la hora de traducir hay que tener en cuenta la distancia cultural entre el texto original y los destinatarios meta. Si se sostiene que la lengua es un reflejo de la cultura, cuando se 
traduce se está realizando una comparación intercultural, es decir, se están comparando lenguas, culturas y sociedades y, por lo tanto, es necesario conocer en profundidad los aspectos socioculturales tanto de la cultura del texto original como los de la cultura del texto meta.

Por ello, así como no podemos desligar la lengua de la cultura, tampoco podemos separar la cultura de la traducción pues, ya sea de manera oral o escrita, siempre tendremos que tener presente la implicación cultural del mensaje que debemos trasladar a la lengua meta, y cuya presencia será mayor o menor, según la intención de la comunicación.

\section{EL APRENDIENTE DE ELE DE NIVEL INICIAL Y LA TRADUCCIÓN}

Estaremos de acuerdo en que las competencias traductoras son múltiples y alcanzarlas todas requiere de tiempo. Para que el estudiante pueda crear esas estrategias, empleamos material auténtico, o bien, preparamos nuestro propio material para centrar la atención en un aspecto particular:

Si es verdad que no sólo los tipos de traducción sino también las estrategias y los métodos de traducir varían según el encargo de traducción, los alumnos tienen que acostumbrarse a trabajar con encargos específicos desde el principio. No es preciso que un encargo en clase siempre sea totalmente realista en el sentido de que así, y sólo así, se da en la realidad profesional. A veces queremos focalizar un determinado problema de traducción y para este fin "fingimos" un encargo específico, o queremos excluir ciertos problemas que no se han discutido todavía. En tales casos hablaríamos de un encargo didáctico (Nord, 2009, p. 232).

Este planteamiento no tiene que llevarse a cabo exclusivamente con estudiantes que cuentan con un nivel avanzado de lengua sino que, en determinados contextos y dependiendo de la estrategia que el docente desee plantear, se puede introducir al estudiante en el campo de la traducción sin que su limitado conocimiento del español suponga un obstáculo para entender algunas ideas.

En el caso que nos ocupa en el presente trabajo, la introducción al mundo de la traducción se ha realizado con alumnos de primer curso de Filología Hispánica en la Universidad Maria Curie Skłodowska de Lublin (Polonia). Dentro del plan de estudios de este grado, los estudiantes tienen diversas asignaturas relacionadas con la traducción: traductología, análisis de textos especializados, aspectos interculturales en la traducción, interpretación. Estas asignaturas se implementan de manera progresiva a medida que el estudiante adquiere la lengua. En el caso del primer $^{1}$ curso de carrera,

\footnotetext{
${ }^{1}$ El presente estudio empírico se realizó durante el curso académico 2019-2020.
} 
la única asignatura relacionada con el campo de la traducción es la llamada "aspectos interculturales en la traducción" durante el segundo semestre 2 .

A efectos prácticos, la duración de la asignatura es de una hora y media a la semana y los estudiantes que participan en ella son alumnos cuyo nivel de español es A1 y rozan o han alcanzado, en algunos casos, el nivel A2. Esto último sucede porque un grupo de estudiantes iniciaron su carrera, teniendo ya nociones de español adquiridas durante los estudios previos al acceso a la universidad. Por tanto, trabajamos con estudiantes que no tienen un nivel homogéneo, lo cual en vez de suponer un problema, se convierte en un elemento a favor a la hora de realizar las tareas asignadas.

Tomando en consideración el grupo en concreto con sus características, no solo en cuanto a su conocimiento lingüístico, sino interesándonos en cómo funcionan como grupo y en el interés que sienten hacia los estudios hispánicos, se planteó como objetivo que el estudiante comenzase a reflexionar entre su lengua materna y la que estaba adquiriendo, es decir, que tomase consciencia de aquello que nos diferencia pero también, de aquello que puede ser similar. Asimismo, se intentó enfatizar en que, en el estudio de una lengua, no solo se comparte una cultura, sino también que existen diferencias intraculturales.

Este objetivo parecía demasiado ambicioso, así como la práctica que se realizó para alcanzarlo, pero contábamos con una serie de elementos externos que favorecían dicho aprendizaje: 1) durante el primer año, además de la lengua, tienen clases de historia y literatura; 2) cuentan con la presencia de tres profesoras nativas provenientes de distintas regiones de España; 3) tienen contacto con hablantes hispanófonos fuera del aula.

Por tanto, para establecer nuestra programación nos propusimos que enlazasen aquellos elementos que estaban aprendiendo en otras asignaturas y los aplicasen en esta desde el punto de vista intercultural. Para ello, la participación del estudiante resultó primordial, pues no se trataba de explicarles estos aspectos interculturales, sino de que identificasen y reflexionasen sobre ellos. Es decir, pensamos que, para traducir, debían ser capaces de realizar los ejercicios ${ }^{3}$ por sí mismos para que fuesen ellos quienes desarrollasen sus propias estrategias.

En un primer momento, los estudiantes se ejercitaron sobre la comunicación base esencial. Ya conocían aquellos aspectos lingüísticos ligados a los saludos, las despedidas, la forma de expresar cortesía con el empleo de usted, pero desconocían la comunicación no verbal relacionada con los distintos contextos en que saludamos, nos despedimos o iniciamos una conversación con otra persona. Además, teniendo en cuenta que existe una serie de apelativos para referirnos a la otra persona, dependiendo del grado de relación que tengamos con ella, así como de la zona de proveniencia

\footnotetext{
${ }^{2}$ Se trata de una asignatura dividida en dos cursos: una primera parte se imparte en el segundo semestre del primer año de Filología Hispánica y, una segunda parte, en el primer semestre del segundo año.

${ }^{3}$ Cabe mencionar que todas las actividades se desarrollaron de forma telemática debido al inicio de la crisis sanitaria.
} 
del hispanohablante, se les expuso distintos contextos para que, en un primer momento, indicasen cómo se desarrollarían dentro de la cultura polaca, y posteriormente, se debatiese sobre la forma en que estas situaciones se llevarían a cabo en la cultura hispana.

Posteriormente, y siguiendo con el comportamiento social, enlazamos la actividad con la importancia que tiene la comida en la cultura hispana, debido a que gran parte de los eventos importantes se realizan en torno a ella. Se trata de un aspecto diferenciador importante, en el que no solo estamos hablando de las distintas formas de alimentarse en ambas culturas, sino de las pautas de comportamiento (pagar la cuenta a medias, invitar a alguien a comer) y los contextos en los que se desarrollan (comidas familiares, con amigos, reuniones de trabajo). Aprovechando este tema, se trataron aspectos como la sobremesa, un elemento característico de la cultura hispana y que no se realiza en la cultura polaca, lo que nos sirvió para realizar una introducción a algunas expresiones idiomáticas relacionas con la comida. Este apartado contempló expresiones como 'ponerse rojo como un tomate' de la que obtuvimos varias opciones de equivalencia por parte del estudiante:

- Być czerwonym jak burak (trad. lit.: ser rojo como una remolacha).

- Robić się czerwonym jak pomidor (trad. lit.: hacerse rojo como un tomate).

- Zrobić się czerwonym jak burak (trad. lit.: hacerse rojo como una remolacha).

- Zaczerwienić się jak pomidor (trad. lit.: enrojecerse como un tomate).

- Robić się czerwony jak burak (trad. lit.: hacerse rojo como una remolacha).

A través de este simple ejercicio, propusimos que el estudiante reflexionase sobre su propia lengua porque la cuestión no era que el 'tomate' se sustituyese por 'remolacha' en polaco, sino entender el motivo por el que empleaban distintos verbos o formas verbales (perfectivo o imperfectivo) de un mismo verbo y dónde radicaba el matiz que las diferenciaba. Con ello, empezamos a hablar sobre la importancia del contexto para decodificar un mensaje.

Para ver estas cuestiones desde un prisma más cercano a la realidad, a lo largo del semestre, se planteó trabajar con la película Ocho apellidos vascos. De todos es sabido el uso que se ha dado a esta película en el aula de ELE. Podemos encontrar varias propuestas por internet en Todoele 4 , Ośrodek Rozwoju Edukacji (ORE) ${ }^{5}$ o la Revista electrónica del lenguaje ${ }^{6}$. La utilización de esta película tenía una doble finalidad: 1) análisis lingüístico 2) análisis no lingüístico. Con respecto al primero, la intención era que los estudiantes escuchasen distintas formas de expresarse en español dentro de un contexto diferente al de una clase de ELE:

\footnotetext{
${ }^{4}$ http://www.todoele.net/actividadescine/Actividad_maint.asp?Actividad_id=107 (10/09/2020)

5 https://www.ore.edu.pl/images/files/KONSPEKT_Descripción\%20física\%20y\%20el\%20carácter. $\operatorname{pdf}(10 / 09 / 2020)$

${ }^{6} \mathrm{http} / / /$ www.revistaelectronicalenguaje.com/wp-content/uploads/2015/03/Vol-I-Art-08.pdf(10/09/2020)
} 
Los juegos de palabras consisten en contrastar estructuras lingüísticas que difieren en el plano semántico, pero coinciden en el plano formal. La similitud formal une significados ajenos, cuya combinación causa sorpresa, equívoco y pronóstico erróneo. Lógicamente es necesario que el receptor descifre la ambigüedad, pues si no activa la segunda lectura del fragmento del discurso, no descubrirá el efecto cómico buscado por el emisor (Martínez Tejerina, 2012, p. 14).

Recordemos que se trata de una película donde se acentúan los estereotipos de los habitantes de dos comunidades autónomas españolas: Andalucía y el País Vasco, y en la que el juego de palabras, el doble sentido, la ironía y el sarcasmo son parte esencial del discurso. Un empleo del lenguaje en el que aparecen en chistes términos como piso franco, costalero, mili, tregua o ETA, y que el aprendiente de español como lengua extranjera no comprenderá si no conoce la relación que tiene con la cultura española, porque como señala nuevamente Martínez Tejerina (2012, p. 13):

Un chiste que hace referencia a un elemento cultural sólo provocará hilaridad si el receptor entiende los mensajes implícitos del mismo, gracias al conocimiento de sus características intrínsecas. Es decir, la efectividad del chiste depende fundamentalmente de la información compartida entre emisor y receptor.

Por ello, es necesario guiar al estudiante para que identifique y obtenga información sobre aquellos aspectos claves del discurso. Tomando en consideración esta cuestión, se dividió a los estudiantes en grupos de 4 formados por miembros con distintos niveles de español para que se documentasen sobre términos señalados en el guion de la película, como los mencionados anteriormente, y los expusiesen posteriormente.

Esta actividad se desarrolló en varias partes, pues, a medida que los estudiantes adquirían más información, la comprensión se hacía más fácil: "el conocimiento lingüístico, en definitiva, puede no resultar suficiente para entender un chiste, pudiéndose hacerse necesario cierto conocimiento compartido entre emisor (los creadores de la versión origen del producto audiovisual en cuestión) y receptor (el espectador) para que tenga éxito" (Martínez Sierra, 2012, p. 65).

No obstante, este no fue el único aspecto que tuvieron que analizar o sobre el que tuvieron que documentarse, ya que para facilitar la comprensión de la película se les incluía una serie de preguntas, como por ejemplo: ¿qué están bailando? ¿Qué canción suena en el móvil de Rafa? ¿A qué juegan los hombres con la pelota y la pared? Este tipo de cuestiones ayudaban a contextualizar las escenas y a entender mejor la realidad que se representaba, como podía ser la imagen del "señorito andaluz".

Una vez que se analizaban dichas cuestiones y se volvían a ver las escenas, se iniciaba un debate sobre cómo vivirían esas situaciones desde la perspectiva polaca. No solo poniendo el foco en el comportamiento o la expresividad, sino en cuestiones his- 
tóricas que han modelado el lenguaje. Con esta práctica, se intentaba reforzar aquella primera idea de contexto surgida durante la actividad de las expresiones idiomáticas e introducir la cuestión del registro. Se tuvo en cuenta que, cuando debían traducir o interpretar de manera profesional, estos aspectos eran indispensables para reproducir el mensaje a la lengua meta de la forma más acertada posible. El hecho de que, durante el primer año, cuenten con la asignatura de Historia de España facilitó la comprensión de muchos elementos tratados en la película.

\section{CONCLUSIÓN}

La dificultad que, en un primer momento, puede entrañar la comprensión de la cultura en un contexto de no inmersión y con aprendientes de español como lengua extranjera de nivel inicial, se difumina a través de la preparación previa del estudiante. Considerando, además, que la enseñanza de la cultura se hace desde una perspectiva traductológica, el estudiante no solamente encuentra el obstáculo de intentar adquirir una realidad cultural determinada intrínsecamente relacionada con la lengua que está aprendiendo, sino que debe realizar una reflexión sobre su propia lengua, poniendo en contraste los conocimientos asociados a la lengua de origen con respecto a la lengua meta para introducirse en conceptos e ideas básicas de la traducción. Una introducción más avanzada y profunda la realizarán a lo largo del segundo curso.

La propuesta didáctica que se ofreció al estudiante resultó positiva desde varios puntos de vista:

1. Empezaron a desarrollar estrategias de documentación que son de gran importancia en la traducción e interpretación profesional.

2. Se iniciaron en la reflexión sobre ambas lenguas y la equivalencia. Es decir, comprendieron que al traducir un término, hay que pensar en la equivalencia funcional, entendida como aquella que servirá para que el mensaje sea comprensible en la lengua meta.

3. Teniendo en cuenta el punto anterior, los estudiantes se familiarizaron con la idea de contexto y registro.

4. La realización de estas actividades favorecieron sus habilidades lingüísticas en otras asignaturas como "Español práctico: expresión e interacción escrita", donde aplicaron expresiones, términos e ideas surgidas en las clases que trataban los aspectos interculturales.

Por consiguiente, consideramos que la introducción temprana de determinados aspectos relacionados con la traducción y la competencia intercultural en niveles A1A2 puede llevarse a cabo con una metodología bien estructurada sin entrar en demasiados tecnicismos, especialmente cuando, a lo largo de sus estudios, se adquieran esos conocimientos específicos. 


\section{BIBLIOGRAFÍA}

Consejo de Europa (2001). Marco Común Europeo de Referencia para las lenguas (MCER). Recuperado de: https://cvc.cervantes.es/ensenanza/biblioteca_ele/marco/cvc_mer.pdf.

Corti, A. (2019). La construcción de la cultura en el Español como lengua extranjera (ELE). Münster: Waxmann.

Diccionario de términos clave de ELE. Recuperado de: https://cvc.cervantes.es/Ensenanza/biblioteca_ele/ diccio_ele/default.htm.

Igareda, P. (2011). Categorización temática del análisis cultural: una propuesta para la traducción. Íkala, revista de lengua y cultura, 16 (27), 11-32. Recuperado de: http://www.scielo.org.co/pdf/ikala/ v16n27/v16n27a2.pdf.

Martínez Sierra, J.J. (2012). Aspectos problemáticos del doblaje del humor. In M.A. Candel Mora, M.A. \& E. Ortega Arjonilla (Eds.), Interculturalidad y traducción en cine, televisión y teatro (pp. 57-80). Valencia: Tirant Humanidades.

Martínez Tejerina, A. (2012). Estrategias traductoras frente a los juegos de palabras: el doblaje de los hermanos Marx en España. In M.A. Candel Mora, M.A. \& E. Ortega Arjonilla (Eds.), Interculturalidad y traducción en cine, televisión y teatro (pp. 9-36). Valencia: Tirant Humanidades.

Nord, C. (2009). El funcionalismo en la enseñanza de traducción. Mutatis Mutandis, 2 (2), 209-243. Recuperado de: https://revistas.udea.edu.co/index.php/mutatismutandis/article/view/2397/2080.

Spychała, M. (2010). El enfoque cultural en la enseñanza y el aprendizaje de español como lengua extranjera (ELE). Studia Romanica Posnaniensia, 37 (2), 71-83. Recuperado de: https://pressto.amu.edu. pl/index.php/srp/article/view/298/3191.

Tatoj, C., Palion-Musioł, A. (2016). Propuestas didácticas para la enseñanza de la interculturalidad en la clase de ELE para los polacos. In J. Wilk-Racięska, A. Szyndler \& C. Tatoj (Eds.), Relecturas y nuevos horizontes en los estudios hispánicos, vol. 4: Lingüistica y didáctica de la lengua española (pp. 274-287). Katowice: Wydawnictwo Uniwersytetu Śląskiego. 